\title{
A specific pattern of splicing for the horse $\alpha$ S1-Casein mRNA and partial genomic characterization of the relevant locus
}

\author{
Dragan Milenkovic, Patrice Martin, \\ Gérard Guérin, Christine Leroux* \\ Institut national de la recherche agronomique, Département de génétique animale, \\ Laboratoire de génétique biochimique et de cytogénétique, \\ Centre de recherches de Jouy, 78352 Jouy-en-Josas Cedex, France
}

(Received 7 August 2001; accepted 3 December 2001)

\begin{abstract}
Mares' milk has a composition very different from that of cows' milk. It is much more similar to human milk, in particular in its casein fraction. This study reports on the sequence of a $994 \mathrm{bp}$ amplified fragment corresponding to a horse $\alpha$ S1-Casein $(\alpha \mathrm{S} 1-\mathrm{Cn}) \mathrm{cDNA}$ and its comparison with its caprine, pig, rabbit and human counterparts. The alignment of these sequences revealed a specific pattern of splicing for this horse primary transcript. As in humans, exons $3^{\prime}, 6^{\prime}$ and $13^{\prime}$ are present whereas exons 5, 13 and 14 are absent in this equine mRNA sequence. BAC clones, screened from a horse BAC library, containing the $\alpha S 1-C n$ gene allowed the mapping of its locus by FISH on equine chromosome 3q22.2-q22.3 which is in agreement with the Zoo-FISH results. Genomic analysis of the $\alpha \mathrm{S1}-\mathrm{Cn}$ gene showed that the region from the second exon to the last exon is scattered within a nucleotide stretch nearly $15-\mathrm{kb}$ in length which is quite similar in size to its ruminant and rabbit counterparts. The region between $\alpha S 1$ - and $\beta$-Cn genes, suspected to contain cis-acting elements involved in the expression of all clustered casein genes, is similar in size $(c a .15-\mathrm{kb})$ to the caprine and mouse intergenic region.
\end{abstract}

horse / $\alpha$ S1-Casein / cDNA / localisation

\section{INTRODUCTION}

Milk, the natural food for new-born mammals obviously contains all of the components necessary for the initial phases of postnatal development. With regards to the protein content of milk, marked qualitative and quantitative

\footnotetext{
* Correspondence and reprints
}

E-mail: cleroux@clermont.inra.fr

Current address: Institut national de la recherche agronomique, Département d'élevage et de nutrition des animaux, Unité de recherches sur les herbivores, Centre de recherches de Theix, 63122 Saint-Genès-Champanelle, France 
(ca. $4 \mathrm{~g} \cdot \mathrm{L}^{-1}$ to $200 \mathrm{~g} \cdot \mathrm{L}^{-1}$ [10]) differences have been observed between species. Caseins $(\mathrm{Cn})$, the major milk proteins in ruminants, are a family of four acidic phosphoproteins $(\alpha \mathrm{S} 1, \alpha \mathrm{S} 2, \beta$ and $\kappa$-Cn; for review see [27]) with relative proportions also varying among species. The amino acid or nucleotide sequences of the four caseins have been determined in a number of species (mainly ruminants and rodents). Multiple alignments of $\alpha \mathrm{S} 1-\mathrm{Cn}$ amino acid sequences from different species, taking into account the exon modular splicing derived from the known structural organisation of the bovine [12], goat [14] and rabbit [11] genes, points to the occurrence of insertion/deletion events [18]. Exon-skipping has been shown to be responsible for such events and for the apparent relatively high structural divergence observed between $\alpha \mathrm{S} 1-\mathrm{Cn}$ from different species as well as for its wide variability in size [19].

Caseins are encoded by four genes physically linked in the order $\alpha \mathrm{Sl}_{-}, \beta-$, $\alpha S 2-$ and $\kappa-C n$. The overall organisation of the casein locus is fairly conserved between bovine, human and mouse species [6,23-25]. Some differences, however, have been described in the distances separating casein genes and their number (an extra $\alpha S 2-C n$-like gene has been detected in the mouse). Regarding the intergenic region, some differences have also been described: the $\alpha S 1-/ \beta$-Cn intergenic region ranges from $c a .10 \mathrm{~kb}$ in the mouse [25] to less than $c a .60 \mathrm{~kb}$ in humans [24]. To unravel the mechanisms that underly the co-ordinated expression of all four casein genes, a detailed knowledge of the casein locus organisation is required. The existence of cis-acting elements in the $\alpha S 1 / \beta$ region involved in and required for the expression of all four casein genes has been suggested [23].

Mares' milk has lower protein and fat contents than ruminant milk [4] and its composition is closer to that of human milk (Miranda et al., unpublished). It has been studied for its potential nutritional properties and its effects on human health. This milk and koumiss, a product of its fermentation, are reported to have potential therapeutic benefits and/or dietetic effects $[13,16]$. Mares' milk can be regarded as an alternative to cows' milk in most children with severe IgE-mediated cows' milk allergy [2].

In contrast to ruminant milk, the mares' milk composition has remained up to now poorly documented, in particular, its caseins composition and structure. Proteomic tools have allowed to characterize the protein fraction of equine milk, clearly demonstrating the presence of $\alpha \mathrm{S} 2-\mathrm{Cn}$ and $\kappa$-Cn [21]. Very recently, the primary structure of $\kappa$ - $\mathrm{Cn}$ isolated from mares' milk by RP-HPLC, has also been reported [9] and the $\beta$-Cn cDNA sequence is now available in data bases (accession number: AF214526). However there is no data regarding the $\alpha \mathrm{Sl}$-Cn sequence. Similarly, no genomic information is available on the casein locus in the horse. Here, we report an equine $\alpha S 1-C n$ cDNA sequence and the comparison with its counterpart from different species as well as the partial casein locus organisation in the horse. 


\section{MATERIALS AND METHODS}

\subsection{RNA extraction from mares' milk cells}

Mares' milk samples $(2 \times 50 \mathrm{~mL})$ were freshly collected and total RNA was extracted directly from pelleted cells after centrifugation at $3500 \times \mathrm{g}$ for $30 \mathrm{~min}$ at $4{ }^{\circ} \mathrm{C}$ essentially according to the procedure described in [3]. Pelleted cells were lysed with $0.5 \mathrm{~mL}$ of denaturing solution. Pellets of RNA were stored in ethanol at $-20^{\circ} \mathrm{C}$. For RNA analysis, the pellet was dissolved in $50 \mu \mathrm{L}$ distilled water.

\subsection{Reverse-transcription, $P C R$ and cDNA sequence analysis}

Total RNA prepared $(5 \mu \mathrm{L})$ from the cellular pellet was reverse transcribed into first strand cDNA as previously described [18]. PCR primers were designed from conserved regions. Owing to the high conservation of the sequence encoding the signal peptide of calcium-sensitive caseins between species, the BT71 primer was chosen to pair with this sequence. From another highly conserved region detected in the 3'-UTR after the alignment of known $\alpha S 1-C n$ cDNA sequences from various species, the BT56 reverse primer was defined, starting 13 to $15 \mathrm{nt}$ upstream of the polyadenylation signal as previously described [18]. DNA fragments obtained after PCR on reversed transcribed mRNA under standard conditions using the $\alpha S 1-C n$ BT56/71 specific primer pair were cloned into pUC18 essentially as previously described [18]. These clones were screened by PCR using the same $\alpha S 1-C n$ primer pair, BT56/71. PCR products, $5 \mu \mathrm{L}$ of each reaction mix, were analysed by electrophoresis. A plasmid showing a $c a .1 \mathrm{~kb}$ amplified fragment was sequenced after purification with a QIAquick PCR kit (Qiagen), using the Prism ready reaction cycle sequencing kits and an ABI 377 automated sequencer (Applied Biosystems Inc.). A comparison of the resulting sequences was searched using BLAST and Align programmes.

Oligonucleotides were provided by Genosys Biotechnology (United Kingdom).

Forward primer sequences were

BT71: 5' ATGAA(A/G)IT(T/C)(T/C)TCAT(T/C)(T/C)T(T/C)(A/G)CCTG 3', Eq1: 5' AGCAGCACTTCATCAAGCGAG 3',

Eq5: 5' AGACAGCCAGAAATCATTCAG 3',

Eq7: 5' CATTCTTGATTTCTCTCCTCA 3',

$\mathrm{Eq} \beta 1: 5^{\prime}$ TATGTATTATACAGCATTCATCTT 3',

Eq $\beta 3$ : 5' GACTCAGCCATGAAGATCCT 3'.

Reverse primer sequences were

BT56: 5' AAATCTGAGT(T/C)ACTGCACACA 3', 
Eq2: 5' TCAGTGTTAATGGGAACAACTTC 3', Eq4: 5' ACATCAAGGGCCATAATTGTG G 3',

Eq8: ATGACACTTACAGAAGAAGCA 3', Eq $\beta 2: 5^{\prime}$ GACTGGTTAGGAAATAGATTC 3'.

BT71, BT56, Eq1, 5, 7, 2, 4 and 8 were used to amplify cDNA and sequence it. All primers named Eq were used to amplify the genomic region.

The letters in brackets represent the degenerescence at the relevant position.

\subsection{Genomic analyses}

To characterize the casein locus, BAC clones containing casein genes were isolated from the Inra horse BAC library [20] by PCR screening using $\alpha \mathrm{S} 1-\mathrm{Cn}$ $(\mathrm{Eq} 7 / \mathrm{Eq} 8)$ and $\beta-C n(\mathrm{Eq} \beta 1 / \beta 2)$ specific primer pairs.

Clones were prepared as described previously $[7,26]$ and their gene content was ascertained by PCR performed on miniprepped BAC DNA with the same screening primers. PCR fragments were purified with the QIAquick PCR purification kit (Qiagen) and sequenced on an ABI 377 automated sequencer (Applied Biosystems Inc.). Homologies to sequences present in the databases were searched for using the BLAST algorithm (www.ncbi.nlm.nih.gov). The BAC insert size was estimated after Not $\mathrm{I}$ digestion followed by field inverted gel electrophoresis (FIGE). BAC clones containing the casein locus were used for fluorescence in situ hybridization (FISH) mapping as described elsewhere [1,7].

Equine genomic DNA was prepared from peripheral blood, as previously described [7]. The Expand ${ }^{\mathrm{TM}}$ long template PCR system of BoehringerMannheim (Meylan, France) was used according to the manufacturer's protocol except that annealing was performed at $55^{\circ} \mathrm{C}$. An aliquot $(5 \mu \mathrm{L})$ of each reaction mix was analysed by electrophoresis, then amplified DNA $(10 \mu \mathrm{L})$ was digested with one of the following restriction enzymes: PstI, PvuII under conditions specified by the supplier. The size of digested fragments was determined by electrophoresis in $1 \%$ agarose gel.

\section{RESULTS AND DISCUSSION}

\subsection{Nucleotide sequence of the cDNA encoding equine $\alpha S 1-C n$}

To decipher the equine $\alpha S 1-C n$ cDNA primary structure, we took advantage of the presence of mammary epithelial cells in milk to isolate RNA.

After cloning of amplified fragments, recombinant plasmids were screened using $\alpha S 1-C n$ specific primers to identify a clone containing a horse $\alpha S 1-C n$ cDNA. The sequencing of the identified $\alpha S 1-C n$ cDNA insert reveals that the amplified fragment was $1018 \mathrm{bp}$ in length. The accession number of the obtained $\alpha S 1-C n$ cDNA sequence, reported here, is AY049939. Due to the strategy used, the $5^{\prime}$ extremity of the cDNA amplified fragment corresponds 
to the sequence encoding the signal peptide and therefore this cDNA lacks $5^{\prime}$ UTR. The coding region stretches over $627 \mathrm{bp}$ coding for a 208 amino acid (aa) residues protein including the 15 aa residues of the signal peptide. Therefore, the mature horse $\alpha \mathrm{S} 1-\mathrm{Cn}$ is 193 aa residues long. Most of the $3^{\prime}$-UTR is included in the amplified cDNA fragment which stretches out $391 \mathrm{bp}$ past the TGA stop codon.

Multiple alignments of the cDNA sequences from different species (Fig. 1), taking into account the exon modular splitting derived from the known structural organisation of genes as proposed by [19] points to constitutive horse specific exon-skipping events. Indeed, exons 5, 13 and 14 (numbering of the caprine gene) are lacking whereas the others including exons $3^{\prime}, 6^{\prime}$ and $13^{\prime}$ are present. Exons $3^{\prime}$ and $6^{\prime}$ are conserved during splicing as in the rabbit whereas they are absent in ruminant mRNA. Conversely, exon $13^{\prime}$ which was first detected in humans [18] is present in horse $\alpha S 1-C n$ mRNA as in the pig. It is worth noting that exon 13, which is a duplication of exon 10 in ruminants, is absent in the horse cDNA sequence reported here as in humans, pigs and rabbits. This event could be due to mutation(s) in the splice site sequence surrounding this exon or to the absence of this duplication in equine species. This horse exon-skipping pattern is more similar to that exhibited by its rabbit counterpart (except for exons 13 and 14) than to its caprine or bovine counterpart. The specificity of the horse $\alpha$ Sl-Cn pattern of splicing, reported here, resides in exon 5-skipping which is not observed in the caprine, rabbit, pig and human species. However, this work could not provide evidence of the absence of multiple alternative processed transcripts as described in goat $[5,14]$. Moreover, due to the lack of polymorphism analysis, we cannot exclude that genetic variability exists. The $\alpha S 1-C n$ splicing pattern presented here is the first described in the horse. The present transcript most probably corresponds to the longer of the two, major $\alpha \mathrm{S} 1-\mathrm{Cn}$ proteins identified in the mares' milk (Miranda et al., unpublished). Regarding the multiplicity of alternative splicing described in different species for this gene (see review [19]), we can guess that other patterns could exist in the horse.

Furthermore, it is worth noting that 3 or 6 nucleotide deletions occur at the $5^{\prime}$ or $3^{\prime}$ extremities of the horse exons 4, 6 and 11 (Fig. 1). In goats, it was proposed that such events are due to the usage of cryptic $5^{\prime}$ or $3^{\prime}$ splice sites leading to the elimination of the first or the last codon of exons [14]. This event could be due to inaccurate splicing by promoting selection of cryptic splice sites and/or by equine specific mutation changing this splice site sequence. These phenomena seem to be rather frequent with $\alpha S 1-C n$ transcripts occurring in most of the species examined so far. Exon-skipping and cryptic splice site usage result in an interspecies variability of the $\alpha \mathrm{S} 1-\mathrm{Cn}$ structure.

Regarding cDNA sequence comparison, different types of analysis of similarity were performed. A global analysis with the entire sequences gave a 


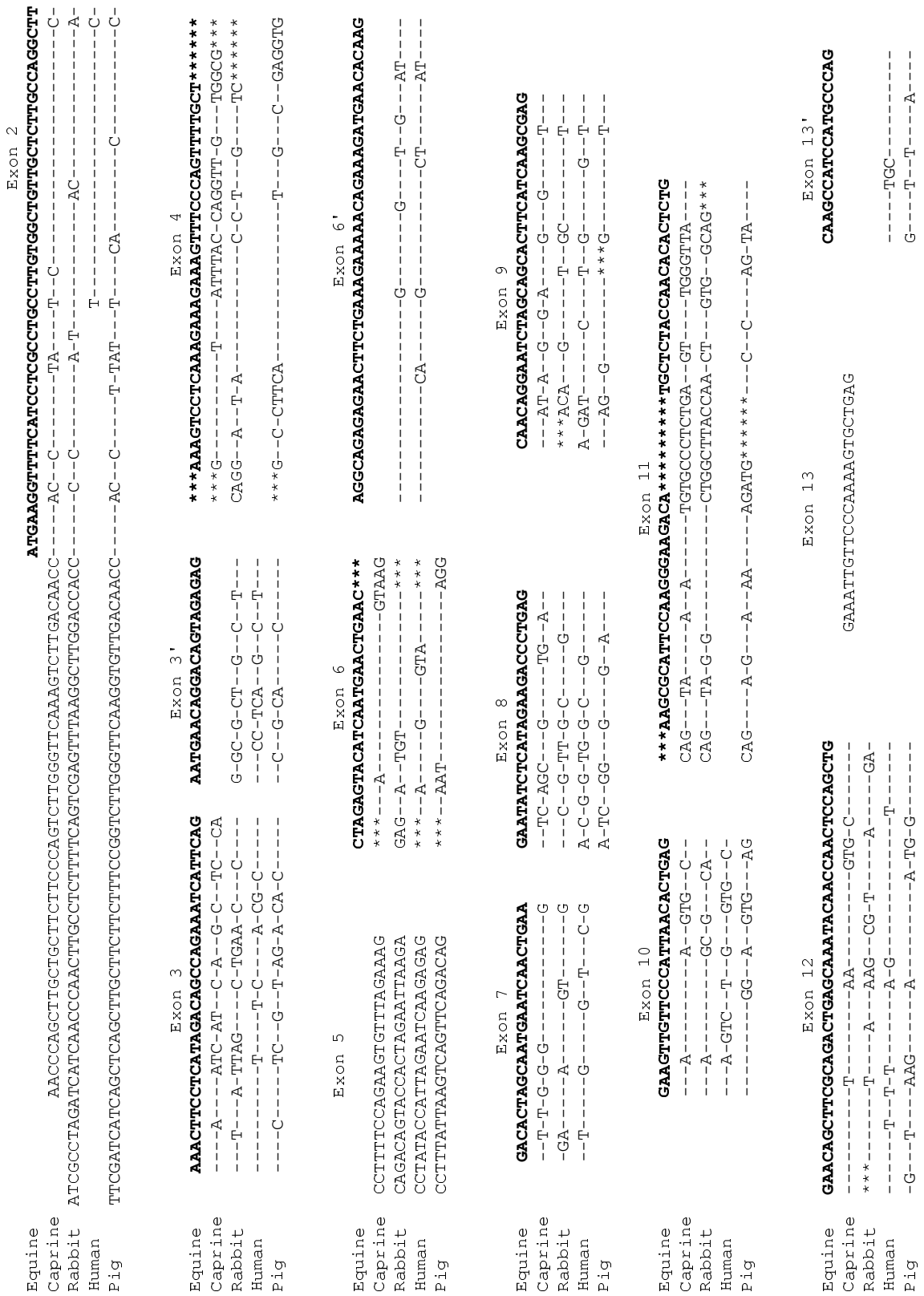

Figure 1. Sequence alignment of equine (AY049939), caprine (x59836), rabbit (x13042), human (x98084) and pig (x54973) $\alpha$ S1-casein cDNAs. Sequences are split into blocks to visualize the exonic modular structure as deduced from known splice junctions of the relevant genes. Reference sequence in bold is that of the horse. - indicate nucleotides identical to those of the reference sequence. * are inserted gaps introduced to maximize the alignment. 

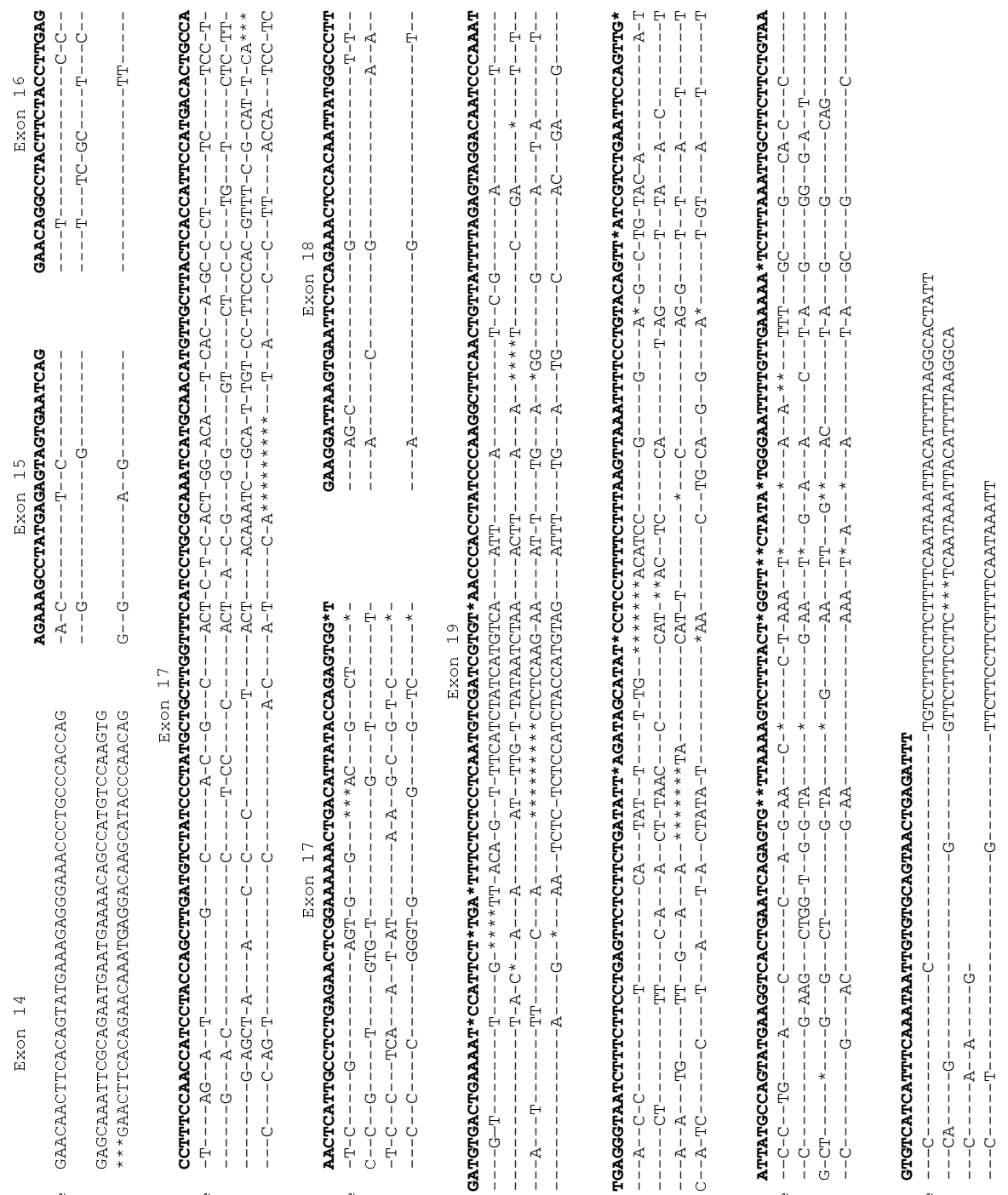

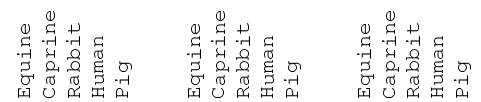

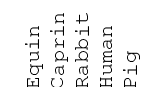

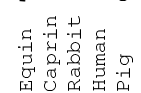

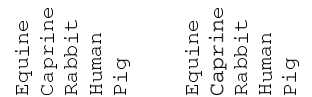

Figure 1. Continued.

degree of similarity with caprine, rabbit, human and pig full-length cDNA of $c a$. $60 \%$. Due to the exon-skipping events, this global comparison does not reflect biological reality. The comparison of common exon sequences reveals higher degrees ( $c a .75 \%)$ of similarity between the horse and other species. Furthermore, sequence comparisons taking into account the exon modular structure of the cDNA show a similarity ranging between 61 to $93 \%$ 
depending on the exons and the species compared. In particular, the equine exon 9 sequence which encodes the highly conserved multiple phosphorylation site of the protein has around $75 \%$ similarity with its caprine, rabbit and pig counterpart. Surprisingly, similarity with human exon 9 is lower (less than $65 \%)$. It is worth noting that equine exons 15 and 18 show a high similarity (> 80\%) with the other species (Fig. 1).

\subsection{Partial characterization of the casein gene locus}

Using PCR to screen the Inra horse BAC library, the $\alpha S 1-C n$ (Eq7/Eq8) primers identified 12 clones likely to contain the relevant gene. One BAC (593-G-3) clone was studied in more detail. The insert size of this clone, estimated after NotI digestion followed by field inverted gel electrophoresis (FIGE) analysis, was $c a .90 \mathrm{~kb}$. The presence of the $\alpha S 1-C n$ gene in this clone was confirmed by sequencing of the PCR product obtained. A specific hybridisation signal obtained by FISH using this clone as a probe was observed on the equine chromosomal region 3q22.2-q22.3 (ECA3) after examination of the metaphase spread. This result is in agreement with Zoo-FISH analyses [22] and comparative mapping data [20]. Indeed, the casein locus was localised on the 6q31 bovine chromosomal region [28], on caprine 6q32 [8] and on human 4q21.1 [17], which are orthologous of ECA3.

With respect to the regulation of expression of the four casein genes, the $\alpha S 1 / \beta$ region suspected to contain cis-acting elements was studied. Since the $\beta-C n$ gene was not detected in BAC 593-G-3, a second screening of the BAC library was performed using primers specific for $\beta$-Cn gene $(\mathrm{Eq} \beta 1 / \mathrm{Eq} \beta 2)$. Six clones were shown to contain the $\beta$-Cn gene and one (577-C-4) of them included both the $\alpha S 1-C n$ and the $\beta$-Cn genes. The size of the insert was estimated by FIGE to be $c a$. 82-kb. Given the close proximity of the caprine, bovine and mouse $\alpha \mathrm{SI}-\mathrm{Cn}$ and $\beta$-Cn loci [15,23,25], the size of this intergenic region in the horse was evaluated using long-range PCR. Electrophoresis of PCR products was obtained using Eq7 (matching the $5^{\prime}$ of the last exon of the $\alpha S 1-C n$ gene) and $\mathrm{Eq} \beta 1$ (matching of the exon 8 sequence of the $\beta$-Cn gene; accession number AF214526) revealed an amplified fragment, the size of which was estimated to be $c a$. 11.2-kb after PstI, PvuII digestion and gel electrophoresis. This result (Fig. 2) demonstrates that these two genes are also convergently transcribed as it was first shown in caprine [15], bovine [23], mice [25] and human [24]. Interspecies comparison of the $\alpha S 1 / \beta-C n$ region revealed its conservation during evolution. Only the distance separating these two casein genes is quite different. In horses, the size of this intergenic region is between that of its mouse counterpart (10 kb, [25]) and its ruminant (12 kb in caprine [15] and $20 \mathrm{~kb}$ in bovine [23]) counterparts. In humans this 


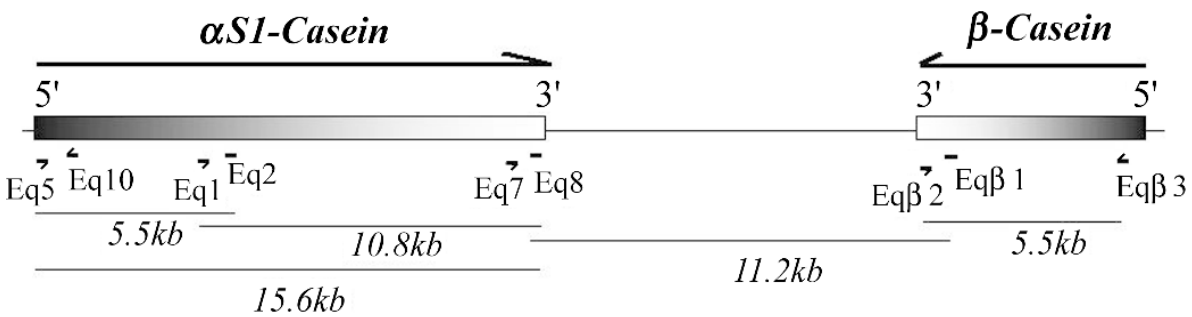

Figure 2. Relative position and orientation of $\alpha \mathrm{S} 1$ - and $\beta$-casein genes. The genes are represented as rectangles, orientated by arrows on the top. Names, position and orientation of primers as well as size of amplified fragments are also given.

region seems to be larger since the $\alpha S 1$ - and $\beta$-Cn gene appeared to be $60 \mathrm{~kb}$ apart [24].

In the same way, the size of the $\alpha S 1-C n$ gene has been determined by longrange PCR using primer pairs Eq5 (matching exon 2)/Eq2 (matching exon 10); Eq1 (matching exon 9)/Eq8 (matching the last exon) and Eq1/Eq2 (Fig. 2). The sizes of the amplified fragments estimated after PstI, PvuII digestion and gel electrophoresis were $c a$. 5.5-, 10.8- and 0.7-kb, respectively. These results suggested that the size of the $\alpha \mathrm{S} 1-\mathrm{Cn}$ gene is at least $15-\mathrm{kb}$ without the region spanning exons 1 to 2 . The size of this segment is quite similar to those determined for ruminants and rabbits ( $c a .15-\mathrm{kb})$.

Lastly, the size of the $\beta$-Cn locus was determined by long-range PCR using the primers $\mathrm{Eq} \beta 3$ (matching with exon 2) and $\mathrm{Eq} \beta 2$ (matching with the $3^{\prime}$ extremity of the gene). Gel electrophoresis of the PCR product revealed that the size of this region, $5.5 \mathrm{~kb}$ in the horse, is at least $1 \mathrm{~kb}$ shorter than its ruminant counterpart. The characterisation of this gene is under investigation to determine the deletion site.

\section{CONCLUSION}

The results presented here are in agreement with the hypothesis that exonskipping and cryptic splice site usage outcome in an interspecies variability of the $\alpha \mathrm{Sl}-\mathrm{Cn}$ [19]. We have described here a horse specific pattern of $\alpha \mathrm{SI}-\mathrm{Cn}$ primary transcript splicing. Nevertheless, we cannot exclude the existence of other patterns due to the extensive alternative splicing of this gene described in other species. We have also analysed the genomic organisation of a part of the casein locus which presents a large similarity with the loci of the other species described so far. This knowledge provides tools to study the regulation of the casein gene cluster in equine species and the homologous cDNA sequence leads us to study the $\alpha S 1-C n$ alternative splicing in the horse. 


\section{ACKNOWLEDGEMENTS}

We thank Mr Dinard for providing us with mares' milk. We express our gratitude to Anne Oustry-Vaiman for FISH experimentation; Corinne GiraudDelville and Séad Taourit for their technical assistance in sequencing and Johann Laubier for his help in preparing PCR fragments. We would like to thank Fergal Lawless for revising the English version of the manuscript.

\section{REFERENCES}

[1] Bahri-Darwich I., Vaiman D., Olsaker I., Oustry A., Cribiu E.P., Assignment of bovine synteny groups U27 and U8 to R-banded chromosome 12 and 27, respectively, Hereditas 120 (1994) 261-265.

[2] Businco L., Giampietro P.G., Lucenti P., Lucaroni F., Pini C., Di Felice G., Iacovacci P., Curadi C., Orlandi M., Allergenicity of mare's milk in children with cow's milk allergy, J. Allergy Clin. Immunol. 105 (2000) 1031-1034.

[3] Chomczynski P., Sacchi N., Single-step method of RNA isolation by acid guanidinium thiocyanate-phenol-chloroform extraction, Anal. Biochem. 162 (1987) $156-159$.

[4] Doreau M., Le lait de jument, INRA Prod. Anim. 4 (1991) 297-302.

[5] Ferranti P., Addéo F., Malorni A., Chianese L., Leroux C., Martin P., Differential splicing of pre-messenger RNA produces multiple forms of mature caprine $\alpha \mathrm{S} 1$ casein, Eur. J. Biochem. 249 (1997) 1-7.

[6] Fujiwara Y., Miwa M., Nogami M., Okumura K., Nobori T., Suzuki T., Ueda M., Genomic organization and chromosomal localization of the human casein gene family, Hum. Genet. 99 (1997) 368-373.

[7] Godard S., Schibler L., Oustry A., Cribiu E.P., Guérin G., Construction of a horse BAC library and cytogenetical assignment of 20 type I and type II markers, Mamm. Genome 9 (1998) 633-637.

[8] Hayes H., Petit E., Bouniol C., Popescu P., Localization of the alpha-S2-casein gene (CASAS2) to the homoeologous cattle, sheep, and goat chromosomes 4 by in situ hybridisation, Cytogenet. Cell Genet. 64 (1993) 281-285.

[9] Iametti S., Tedeschi G., Oungre E., Bonomi F., Primary structure of $\kappa$-casein isolated from mares' milk, J. Dairy Res. 68 (2001) 53-61.

[10] Jenness R., Holt C., Casein and lactose concentrations in milk of 31 species are negatively correlated, Experientia. 43 (1987) 1015-1018.

[11] Jolivet G., Devinoy E., Fontaine M.L., Houdebine L.M., Sequence of rabbit $\alpha$ s1-casein cDNA, Nucleic Acids Res. 16 (1992) 11813-11813.

[12] Koczan D., Hobom G., Seyfert H.M., Genomic organization of the bovine $\alpha$ s1casein gene, Nucleic Acids Res. 18 (1991) 5591-5596.

[13] Kurmangalinov S.M., Aïdarkhanov B.B., Sharmanov A.T., Taspolatov B.K., Chuvakova T.K., Saparov A.S., Immunomodulating properties of woman, cow and mare milks, Pediatrija 4-6 (1992) 65-68.

[14] Leroux C., Mazure N., Martin P., Mutations away from splice sites recognition sequences might cis-modulate alternative splicing of goat $\alpha$ s1-casein transcripts. Structural organization of the relevant gene, J. Biol. Chem. 267 (1992) $6147-$ 6157. 
[15] Leroux C., Martin P., The caprine $\alpha$ s1- and $\beta$-casein genes are 12-kb apart and convergently transcribed, Anim. Genet. 27 (1996) 93.

[16] Lozovitch S., Medical uses of whole and fermented mare milk in Russia, Cultured Dairy Products J. 30 (1995) 18-21.

[17] McConkey E.H., Menon R., Williams G., Baker E., Sutherland G.R., Assignment of the gene for beta-casein (CSN2) to $4 \mathrm{q} 13 \rightarrow \mathrm{q} 21$ in humans and $3 \mathrm{p} 13 \rightarrow \mathrm{p} 12$ in chimpanzees, Cytogenet. Cell Genet. 72 (1996) 60-62.

[18] Martin P., Brignon G., Furet J.P., Leroux C., The gene encoding $\alpha$ s1-casein is expressed in human mammary epithelial cells during lactation, Lait 76 (1996) 523-535.

[19] Martin P., Ferranti P., Leroux C., Addéo F., Non-bovine caseins: quantitative variability and molecular diversity, in: Fox P.F. (Ed.), Advanced Dairy Chemistry: Proteins, 3rd ed., Kluwer Academic/Plenum Publishers, New York, 2002, in press.

[20] Milenkovic D., Oustry-Vaiman A., Lear T.L., Billault A., Mariat D., Piumi F., Schibler L., Cribiu E.P., Guérin G., Cytogenetic localization of 136 genes in the horse: comparative mapping with the human genome, Mamm. Genome 13 (2002) in press.

[21] Miranda G., Mahé M.F., Leroux C., Martin P., Proteomic tools to characterise the protein fraction of equine milk, in proceedings of the Milk protein conference, Vinstra, Norvège, March 30-April 2, 2000.

[22] Raudsepp T., Frönicke L., Scherthan H., Gustavssin I., Chowdhary B.P., ZooFISH delineates conserved chromosomal segments in horse and man, Chromosome Res. 4 (1996) 218-225.

[23] Rijnkels M., Kooiman P.M., de Boer H.A., Pieper F.R., Organisation of the bovine casein gene locus, Mamm. Genome 8 (1997a) 148-152.

[24] Rijnkels M., Meershoek E., de Boer H.A., Pieper F.R., Physical map and localization of the human casein gene locus, Mamm. Genome 8 (1997b) 285-286.

[25] Rijnkels M., Wheeler D.A., de Boer H.A., Pieper F.R., Structure and expression of the mouse casein gene locus, Mamm. Genome 8 (1997c) 9-15.

[26] Schibler L., Vaiman D., Oustry A., Guinec N., Dangy-Caye A.L., Billault A., Cribiu E.P., Construction and extensive characterization of a goat Bacterial Artificial Chromosome library with threefold genome coverage, Mamm. Genome 9 (1998) 119-124.

[27] Swaisgood H.E., Review and update of casein chemistry, J. Dairy Sci. 76 (1993) 3054-3061.

[28] Threadgill D.W., Womack J.E., Genomic analysis of the major bovine casein genes, Nucleic Acids Res. 18 (1990) 6935-6942. 